\title{
O ser humano no transumanismo: elementos ético-antropológicos para um diálogo com a proposta cristã
}

\section{The human being in transhumanism: ethical- anthropological elements for a dialogue with the christian proposal}

Rafael Martins Fernandes*

Pontifícia Universidade Católica do Rio Grande do Sul

Luiz Maria de Barros Coelho Neto**

Universidade Católica do Rio Grande do Sul

Recebido em: 16/02/2020. Aceito em: 31/07/2020.

Resumo: O presente artigo pretende aproximar as compreensões transumanista e cristã de ser humano, comparando-as em suas diferentes propostas e oferecendo a partir daí alguns questionamentos éticos. Para isso, apresenta-se, na primeira parte, uma breve introdução ao movimento transumanista, seguido pela análise das vertentes antropológicas que compõe o seu ideário. Logo depois, aborda-se duas problemáticas de teor ético presentes nesse movimento, a saber: a difícil delimitação entre terapia e melhoramento (enhancement) e a controversa noção de perfeição humana. Na segunda parte do artigo, desenvolve-se brevemente a proposta antropológica cristã a partir da noção bíblica de imago Dei. A comparação entre as compreensões antropológicas transumanista e cristã não é exaustiva, mas é útil para fazer notar algumas diferenças, como

* Doutor em Teologia (Pontifícia Universidade Lateranense, PUL, Roma, Itália, 2018). Mestre em Teologia (Pontifícia Universidade Católica do Rio Grande do Sul, PUC-RS, Porto Alegre, RS, 2014). Graduado em Teologia (Pontifícia Universidade Católica do Rio Grande do Sul, PUC-RS, Porto Alegre, RS, 2008). Graduado em Filosofia (Pontifícia Universidade Católica do Rio Grande do Sul, PUC-RS, Porto Alegre, RS, 2003).

E-mail: padrerafaelfernandes@gmail.com

** Mestrando em Teologia (Pontifícia Universidade Católica do Rio Grande do Sul, PUC-RS). Graduado em Teologia (Dupla Titulação: Pontifícia Universidade Católica do Rio Grande do Sul, PUCRS, Porto Alegre, RS e Pontifícia Universidade Lateranense, PUL, Roma, Itália, 2014). Graduado em Filosofia (Pontifícia Universidade Católica do Rio Grande do Sul, PUC-RS, Porto Alegre, RS, 2009).

E-mail: barroslui@gmail.com 
a tendência do transumanismo à mecanização do indivíduo e a consequente relativização do princípio cristão de dignidade do corpo humano. Identifica-se nesses elementos um neognosticismo tecnológico. Em contrapartida, a análise da antropologia cristã aponta para uma proposta de sentido para o ser humano, dada a partir de um humanismo integral e solidário.

Palavras-chave: Ser humano. Transumanismo. Melhoramento. Antropologia cristã. Imago Dei.

Abstract: The present article intends to approximate the transhumanist and Christian understandings of human beings, comparing them in their different proposals and offering from there some ethical questions. For this, the first part presents a brief introduction to the transhumanist movement, followed by the analysis of the anthropological aspects that make up its ideas. Soon after, two ethical issues present in this movement are addressed, namely: the difficult delimitation between therapy and enhancement and the controversial notion of human perfection. In the second part of the article, the Christian anthropological proposal is briefly developed from the biblical notion of imago Dei. The comparison between transhumanist and Christian anthropological understandings is not exhaustive, but it is useful to point out some differences, such as the tendency of transhumanism towards the mechanization of the man and the consequent relativization of the Christian principle of human body dignity. A technological neognosticism is identified in these elements. In contrast, the analysis of Christian anthropology points to a proposal of meaning for the human being, given from an integral and solidary humanism.

Keywords: Human being. Transhumanism. Enhancement. Christian anthropology. Imago Dei.

\section{Introdução}

O movimento transumanista propõe uma concepção de homem como interventor na evolução de sua própria espécie. A proposta de que a espécie humana se automanipule não é nova, mas os atuais avanços tecno-científicos possibilitam que essa ideia alcance resultados práticos como jamais se viu. Com ventos tão favoráveis, o movimento cresce em adeptos e em importância diante da sociedade. Suas ideias têm atraído não apenas a atenção de curiosos e cientistas, mas também de investidores milionários dispostos a gastar as suas fortunas na aquisição de novas técnicas de manipulação. Então, conhecer o movimento e sua proposta antropológica torna-se algo necessário, sobretudo para as ciências humanas que possuem como um de seus objetivos dialogar com tecnólogos e cientistas, escutando e propondo princípios e critérios que deem um sentido autenticamente humano aos novos desenvolvimentos científicos.

Dentro desse cenário, existem os debates entre bioconservadores e bioprogressistas. Outra discussão gira em torno dos limites da realidade virtual e o uso da Inteligência Artificial, que poderá gerar uma massa sem 
precedentes de desempregados. Os debates também atingem o campo teológico, especialmente porque os defensores do transumanismo perseguem os mesmos objetivos religiosos, isto é, a resolução dos problemas centrais da humanidade, como a superação do sofrimento e da morte ${ }^{1}$.

O presente artigo trata da compreensão de ser humano presente no movimento transumanista e algumas questões éticas implícitas, em vista de um diálogo com a proposta antropológica cristã. Para isso, serão apresentados, em um primeiro momento, a origem, a definição e os princípios norteadores do transumanismo, seguido da análise das vertentes antropológicas que compõe o ideário desse movimento. Serão abordadas também algumas implicações éticas. Por fim, tratar-se-á da proposta de sentido cristã, iluminada pela noção bíblica de imago Dei, e algumas críticas ao transumanismo que daí derivam.

\section{Definição, origem e princípios do transumanismo}

O transumanismo pode ser classificado como um movimento de base filosófico-científica, cujo projeto é superar os limites humanos impostos pela lei da natureza. Para tal, utiliza a ideia de "aumento" (enhancement) ou melhoramento das capacidades humanas, tornando o homem mais forte, superinteligente, com aumento de sua destreza, de sua capacidade visual e auditiva, podendo obter uma longevidade saudável e, no futuro, a possibilidade de uma vida imortal. O núcleo possibilitador dessa revolução, que exclui qualquer intervenção divina ou espiritual, é chamado de NBIC: N de nanotecnologias, B de biotecnologias, particularmente o sequenciamento do genoma humano e a ferramenta de edição do DNA que se chama Crispr-Cas9. Depois o I, de informática, com o big data e a "internet das coisas". O C é o cognitivismo, isto é, a inteligência artificial (IA), o coração dessas quatro inovações. ${ }^{2}$

Entre os integrantes desse movimento há cientistas, empresários e filósofos. No campo científico, o norte-americano Raymon Kurzweil, ao lado de outros inventores do vale do Silício (EUA), obteve grande

1 Como literatura brasileira e no plano teológico, Érico Hammes faz um bom levantamento da discussão. No âmbito da bioética, cita-se Leo Pessini; cf. HAMMES, Érico. Transumanismo e Pós-humanismo: uma aproximação ético-teológica. Perspectiva Teológica, Belo Horizonte, v. 50, n. 3, p. 431-452, 2018. PESSINI, Leo. Bioética e o futuro pós-humano: Ideologia ou utopia, ameaça ou esperança? Encontros Teológicos, Florianópolis, n. 67, p. 107-130, 2014.

2 FERRY, Luc. A Revolução transumanista: entrevista concedida a Jorge Forbes para o prefácio da edição brasileira do livro A Revolução transumanista. In: Instituto da Psicanálise Lacaniana, 2018. Disponível em: http://www.ipla.com.br/conteudos/ artigos/a-revolucao-transumanista/. 
sucesso em suas pesquisas, algo que atraiu um número substancial de novos adeptos para o movimento, sobretudo nas décadas de 1990 e 2000. Não faltam investidores dispostos a lucrar com as descobertas. Elon Musk, fundador da Tesla, é um verdadeiro visionário, investindo fortunas na indústria espacial para uma futura colonização no espaço e em pesquisas sobre a interface computador-cérebro. No campo filosófico, destacam-se ideólogos como Nick Bostron, David Pearce e Max More. Eles qualificam o transumanismo como um movimento humanista, mesmo que suas ideias afirmem um futuro pós-humano ${ }^{3}$.

Há um fundo religioso nos escritos desses ideólogos. Bostron recorre à história da religião para traçar os antecedentes do transumanismo. Ele cita rituais fúnebres, mitos gregos, como o de Prometeu e outras tradições religiosas da antiguidade (poemas de Gilgamesch) para afirmar um significado perene contido nos ideais do transumanismo. ${ }^{4}$ Seguindo Érico Hammes 5 , os primeiros usos da palavra "transumanismo" confirmam essa motivação religiosa. O canadense Willian D. Lighthall, em artigo escrito em $1940^{6}$, toma o termo "transumanar" da descrição do paraíso de Dante Alighieri na "Divina Comédia", embasada em 2Cor 12,4 , para demonstrar a conotação religiosa da nova "filosofia metafísica progressista" proposta por ele. Na mesma perspectiva, o biologista Julian Huxley (1887-1975), intitulou o seu ensaio de 1959 como "Garrafas novas para vinho novo"7 fazendo alusão à passagem evangélica "à vinho novo, odres novos", com a qual o cristianismo afirma ser a religião da novidade. Huxley inverte essa interpretação, ao propor o "transumanismo" como a crença realmente capaz de trazer o "novo" para a história. Tais escritos fazem considerar que, na origem e desenvolvimento do transumanismo, há uma fé secularista e uma esperança de salvação fundada na biotecnologia. ${ }^{8}$

3 Para uma maior explicitação do transumanismo como parte integrante dos humanismos modernos, ver: ANTONIO, K. F. Transhumanismo e suas oscilações prometeico-faústicas: tecnoapoteose na era da tecnociência demiúrgica. Natal: PPGFIL, 2018. p. 104. Disponível em: https://issuu.com/j00kun/docs/keoma_ferreira_antonio_-transhumanismo_e_suas_osc. Acesso em: 5 jul. 2020.

4 BOSTRON, N. A History of Transhumanity Thought. 2011, p. 1 e 2. Disponível em: https://www.nickbostrom.com/papers/history.pdf. Acesso em: 5 jul. 2020.

5 Cf. HAMMES E. Transumanismo e pós-humanismo: uma aproximação ético-teológica. Perspectiva Teológica, Belo Horizonte, v. 50, n. 3, p. 431-452, Set.-Dez. 2018.

6 Cf. LIGHTHALL, W. D. The Law of Cosmic Evolutionary Adaptation: An Interpretation of Recent Thought. Ottawa: Royal Society of Canada, 1940.

7 HUXLEY, J. New Bottles for New Wine. London: Chatto and Windus, 1957.

8 "A dimensão do sagrado e da religiosidade encontra-se muitas vezes presente nas esferas laica e profana, cumprindo nelas uma função simbólica e de significação. Por seu lado, as ciências sociais veem com cautela o uso desta constatação como método para a compreensão desta outra faceta dos fenômenos científicos, políticos e 
Mesmo que os seus principais ideólogos expressem uma motivação religiosa de fundo, o transumanismo não é uniforme quanto a seus objetivos. Tem-se os moderados e os radicais. ${ }^{9}$ Os mais moderados restringem os seus objetivos ao tempo presente, buscando apenas técnicas de melhoramento das condições humanas. Entre eles, há adeptos de religiões, como os associados da Christian Transhumanist Association ou da Mormon Transhumanist Association..$^{10}$ Os mais radicais, por sua vez fixam o seu propósito no futuro, apostando as energias e muito dinheiro na cyborguização do homem. Para esses, o futuro é a evolução em uma super-espécie humana que alcançaria a imortalidade. Entre os expoentes dessa ala mais radical, citam-se os extropianos, encabeçados por Max More ${ }^{11}$, e os transtropianismo, um grupo de extrema-direita favorável à aplicação da neoeugenia ${ }^{12}$.

Buscando definir quais são as crenças e princípios básicos que unem as diferentes correntes, em 1998, um grupo internacional de transumanistas publicou uma Declaração Transumanista ${ }^{13}$ disposta em oito artigos. Entre esses princípios, cita-se: a fé na ciência para a superação dos problemas cruciais da humanidade; renúncia a posições políticas extremistas que colocariam em risco a espécie humana; a afirmação de uma moral liberal, na qual cada indivíduo é livre para optar pelo uso das novas tecnologias de reprodução, bem como a adesão a procedimentos criônicos, de aumento de memória, de extensão da vida e outros.

sociais, no que se convencionou chamar de 'religiosidades seculares' ou 'sacralidade laica'. No entanto, julgamos que esta perspectiva pode esclarecer uma outra faceta destas realidades consideradas como não religiosas, revelando - para além de sua autorreferência, de seus aspectos evidentes e de seus reducionismos - dimensões de um imaginário e de produção de sentido também constitutivas destas realidades." (CAMURÇA, Marcelo. 'Religiosidades científicas' hoje: entre o secular e o religioso. In: CRUZ, Eduardo R. da. Teologia e Ciências Naturais: Teologia da Criação, Ciências e Tecnologia em diálogo. São Paulo: Paulinas, 2011).

9 Para uma análise pormenorizada das diferentes vertentes do transumanismo, ver: ANTONIO, K. F., 2018, p. 139-283. Disponível em: https://issuu.com/j00kun/docs/ keoma_ferreira_antonio_-_transhumanismo_e_suas_osc. Acesso em: 5 jul. 2020.

10 Tais associações possuem seus respectivos sites: Christian Transhumanist Association: https://www.christiantranshumanism.org/; Mormon Transhumanist Association: https:// transfigurism.org/. Acesso em: 5 jul. 2020.

11 Fundada em 1990, possui princípios otimistas em relação à capacidade de desenvolvimento transumano, como o progresso perpétuo; cf. MORE, M. Principles of Extropy. 2003. Disponível em: https://web.archive.org/web/20131015142449/http://extropy.org/ principles.htm. Acesso em: 5 jul. 2020.

12 ANTONIO, K. F., 2018, p. 139-283. Disponível em: https://issuu.com/j00kun/docs/ keoma_ferreira_antonio_-_transhumanismo_e_suas_osc. Acesso em: 5 jul. 2020.

13 Para acessar os oito princípios da Declaração Transumanista: BAILY, Doug. et al. Transhumanist Declaration. Disponível em: https://humanityplus.org/philosophy/ transhumanist-declaration/, 1998. 
Como se vê, as diferentes correntes transumanista convergem para a compreensão de ser humano auto manipulável e evolutiva, rumando para o estágio pós-humano. A aproximação com o movimento pós-humanista é indubitável e a diferença entre esses é que o primeiro se apresenta identificado com o aspecto da transição e o segundo define-se em conformidade com a meta. ${ }^{14}$

\section{Qual(is) antropologia(s) o transumanismo apresenta?}

Existem dificuldades na hora de apreender a visão transumanista de ser humano. Isso acontece, porque o movimento apresenta crenças e compreensão antropológica muito dinâmicas e voláteis. O conceito tradicional de "natureza humana", que tende para um significado de teor estático, é rejeitado, o que também dificulta o diálogo com as religiões e a metafísica tradicional ${ }^{15}$. Não é objetivo fazer aqui um estudo antropológico exaustivo. Quer-se apenas acenar para alguns aspectos e nuances que possibilitem uma compreensão mais clara sobre a(s) antropologia(s) do movimento em questão.

Primeiramente, acena-se para os humanismos que originaram o transumanismo. Picco della Mirandola é considerado o pai do humanismo renascentista. Em seu célebre discurso sobre a dignidade do ser humano (1486), enfatizou uma ideia de excelência e superioridade do ser humano no plano do criado, pelo fato de ser concedido ao homem

14 O Pós-Humanismo possui uma trajetória conceitual na literatura diferente da Transumanista e, por isso, merece um estudo em separado, ao qual não nos propomos neste ensaio. Erico Hammes afirma a existência de no mínimo duas vertentes de significado pós-humanista: o cultural-filosófico e o tecnocientífico; cf. HAMMES E., 2018, p. 437; ver também RANISCH, Robert; SORGNER, S. Lorenz (org.). Post - and Transhumanism: an introduction. [S. I.]: Peter Lang Edition, 2014.

15 O conceito de "natureza humana", concebido de modo estático, não se sustenta segundo a dinâmica das ciências modernas, como a Neurociência, a Genética, a Antropologia Cultural, saberes que embasam o transumanismo. Na própria teologia existem autores que tem procurado explicitar um uso do conceito de "natureza" que seja mais dinâmico, como, por exemplo Karl Rahner e, ultimamente, a Comissão Teológica Internacional; ver HAMMES E., 2018, p. 440; RAHNER, K. Sämtliche Werke: Verantwortung der Theologie. Im Dialog mit Naturwissenschaften und Gesellschaftstheorie: BD 15. Freiburg: Verlag Herder, 2020. V. 15; COMISSÃO TEOLÓGICA INTERNACIONAL. Em busca de uma ética universal: novo olhar sobre a lei natural. n. 64-75. Disponível em: http://www.vatican.va/roman_curia/congregations/ cfaith/cti_documents/rc_con_cfaith_doc_20090520_legge-naturale_po.html. Acesso em: 12 jul. 2020. Quanto ao conceito de "pessoa", esse apresenta-se ainda mais difícil de ser explicitado em uma cultura plural e pós-moderna que vivemos hoje. 
exclusivamente o poder de autodeterminar-se. ${ }^{16}$ Tal pensamento, de matriz cristã, foi o propulsor do humanismo iluminista e liberal que se formou nos séculos XVII e XVIII, cujas crenças estão centradas no indivíduo, em sua capacidade racional e em sua liberdade, bem como reivindicam a satisfação das necessidades e desejos de bem-estar. $\mathrm{O}$ cogito ergo sum de René Descartes (1596-1650) torna-se um exemplo paradigmático da concepção de ser humano conformada à racionalidade. Com uma fundamentação subjetivista, o cogito ergo sum expressa uma imagem de indivíduo demasiado autorreflexiva, que obscurece outras dimensões humanas, como a corporalidade e a relacionalidade. $\mathrm{O}$ corpo acaba por se reduzir a uma extensão da consciência (res extensa), que, por sua vez, vai gradativamente se distanciando dos condicionamentos impostos pela natureza.

Para pôr em prática o novo credo iluminista, foi-se, de uma parte, buscando a libertação das crenças cristãs e da concepção medieval de mundo subordinadas a um Deus transcendente. De outra parte, formou-se um modelo de sociedade que lhe fosse correspondente. A criação do Estado moderno, a revolução industrial e o desenvolvimento das ciências empíricas ofereceram as condições ideais para a formação de um modus vivendi secularizado, crente no valor absoluto do indivíduo. Contudo, esse humanismo das Luzes mostra-se ambíguo: a maior liberdade diante dos condicionamentos da natureza, da religião e até mesmo da tutela parental, deve ser paga com alto custo, visto que o homem seguiu um modo de vida industrial, que tende à mecanização do humano. ${ }^{17}$

No transumanismo, a imagem de ser humano encontra-se entre a proclamação radical das crenças iluministas e a ruptura com essas. A radicalização do iluminismo aponta para a crescente afirmação da liberdade humana diante dos condicionamentos da natureza e da religião. Nesse sentido, o homem torna-se um animal cada vez mais "desnaturado", inclinado a automanipular o seu corpo pela técnica em função de seus desejos individuais (subjetivismo radical) ${ }^{18}$. A afirmação extrema dos desejos de uma minoria em desenvolver e desfrutar das novas tecnologias, mesmo que isso comporte em uma preocupação desse grupo pela não realização dos direitos básicos da maioria da população mundial

16 PICO DELLA MIRANDOLA, G. Discurso sobre a dignidade do homem. Trad. de Maria de Lurdes Sirgado Ganho. Lisboa: Edições 70, 2001.

17 HARARI, Yuval N. Sapiens: uma breve história da humanidade. 38. ed. Porto Alegre: L\&PM, 2018. p. 236-245; 315-385.

18 Tal explicitação do subjetivismo moderno com suas consequências para a pessoa encontra-se em: COMISSÃO TEOLÓGICA INTERNACIONAL. Em busca de uma ética universal: novo olhar sobre a lei natural. n. 71-74. Disponível em: http://www.vatican.va/ roman_curia/congregations/cfaith/cti_documents/rc_con_cfaith_doc_20090520_legge-naturale_po.html. Acesso em: 12 jul. 2020. 
(alimentação adequada, saneamento, educação), expõe a autocontradição na qual imerge o transumanismo de corte iluminista. ${ }^{19}$

De outra parte, o rompimento de setores ideológicos do transumanismo com o iluminismo demonstra-se pela observação de uma ausência de preocupação com os direitos humanos, visto o entendimento de que a noção ilustrada de ser humano - com sua individualidade e dignidade únicas - é considerada defasada ou ilusória. Está-se diante de anti-humanismos. Ricardo Rivas García cita, entre as correntes filosóficas que põem em dúvida as crenças iluministas sobre o humano, o estruturalismo, e de forma mais radical, o naturalismo, cujo evolucionismo e niilismo de corte nietzscheano formariam parte ${ }^{20}$. O estruturalismo, marcado pela crença em uma imagem de ser humano que é o resultado de estruturas inconscientes e de condicionamentos externos, coloca em dúvida o papel da consciência e da liberdade humanas. No naturalismo e evolucionismo, a crítica às concepções modernas sobre o que seja o humano aprofunda-se: o indivíduo é reduzido a um conjunto de processos causais bioquímicos que permitem ao evolucionista negar o livre-arbítrio e até mesmo a crença na unicidade do indivíduo.

Nesse sentido, alguns estudiosos da neurociência afirmam a tese de que o in-divíduo, na verdade, é dividuo. Ou seja, experiências mostraram que humanos tomam as suas decisões a partir de vozes interiores, por vezes conflitantes entre os hemisférios esquerdo e direito do cérebro. Não existiria assim uma voz única de comando ou um "eu" único. Nem o livre-arbítrio. ${ }^{21}$ Está-se perante um tipo de visão trans-pós-humanista na qual o humano é simplesmente determinado pelas ciências biológicas. A negação do indivíduo como ser "uno" e "livre", torna a ideia de pessoa uma mera ilusão. O que resta é um monismo materialista ${ }^{22}$, cujas consequências podem ser desastrosas.

19 "Em 2002, os norte-americanos gastaram um bilhão de dólares em medicamentos para o tratamento da calvície, em torno de dez vezes mais o total gasto com pesquisa científica para encontrar a cura da malária, que continua matando milhares de pessoas pelo mundo afora." (PESSINI L., 2014, p. 126).

20 RIVAS GARCÍA, Ricardo, La crisis del humanismo: una revisión y reconstrucción de los supuestos del humanismo cristiano, ante los desafíos del antihumanismo contemporáneo. Franciscanum, v. LXI, n. 172, 2019, p. 19.

21 Ver exemplos de experiências em: HARARI, Yuval N. Homo Deus: uma breve história do amanhã, São Paulo: Companhia das Letras, 2016. p. 294-302; 332.

22 "Sim, os pós-humanistas, nesse caso podemos chamá-los assim, são materialistas, filosoficamente falando [...]. Eles são monistas e materialistas, e dizem: é isso aí, não tem de um lado o pensamento e de outro o corpo, é a mesma coisa" (FERRY L., 2018. Disponível em: http://www.ipla.com.br/conteudos/artigos/a-revolucao-transumanista/). 
É interessante observar que ao lado desse anti-humanismo e do subjetivismo radical existe o sonho de um paraíso pós-humano, onde todo sofrimento e carnivorismo predatório poderiam ser eliminados. Para transumanistas mais confiantes, como David Pearce, "se uma Singularidade tecnológica estiver realmente próxima, então a abolição do sofrimento é viável ainda nesse século." ${ }^{23}$

Com essa pretensão de eliminação da carne e do sofrimento, restaria apenas a consciência humana a nível de pensamento puro e que subsistiria em um hardware, ligado a uma rede de computadores universal. Assim corrobora o filósofo Luc Ferry, supondo a elaboração de uma identidade pessoal imortal:

E se conseguíssemos fabricar um cérebro de silicone, esse cérebro seria completamente humano, por assim dizer, ele não teria só o cálculo, ele teria o verdadeiro pensamento [...]. Ele seria como o humano de Sartre: a existência precederia a essência. Ele seria também um ser de história. Então o verdadeiro projeto da Google é fabricar uma pós-humanidade, é o projeto de Kurzweil, é a busca da imortalidade. Porque enquanto só se aumenta a vida humana, permaneceremos mortais. ${ }^{24}$

Críticos, como João Manuel Duque e Hercílio Martins, percebem, nessas considerações utópicas trans-pós-humanas, uma religião de salvação neognóstica. A exemplo do que ocorre na cosmologia gnóstica ${ }^{25}$, as utopias tecnológicas compreendem a matéria e a carne como elementos a serem superados, devendo permanecer apenas a consciência humana pura. Em um processo tecnológico de salvação, somente o espírito ou a ideia permanecerão para sempre. Compreende-se, então, que a insistente recusa da vulnerabilidade da carne e seu desprezo pela dignidade do corpo humano façam parte de um credo neognóstico. Como explica Duque, tanto na gnose quanto no neognosticismo tecnológico transumano, o monismo materialista é aparente, pois a matéria, como princípio

23 PEARCE, David. As cinco razões pelas quais o transumanismo é capaz de eliminar o sofrimento. 2011. Artigo disponível em: https://www.hedweb.com/transhumanism/ cinco-razoes.html. Acesso em: 20 out. 2019.

FERRY, 2018. Disponível em: http://www.ipla.com.br/conteudos/artigos/a-revolucao-transumanista/.

O gnosticismo, corrente filosófica surgida nos séculos I e II da era cristã, entende o mundo como falho ou mal em sua existência material. De outra parte, há uma realidade de ordem espiritual ou ideal, encoberta pela aparente diversidade da matéria, que deve ser conhecida pelo homem a fim de que ele possa ser salvo da corrupção material. O dualismo entre matéria e espírito, na verdade, esconde um monismo idealista no qual só o espírito realmente existe. 
maléfico, não faz parte do mundo verdadeiro. ${ }^{26}$ Em seguimentos mais moderados do transumanismo, elementos de recusa da vulnerabilidade da carne também podem ser percebidos. ${ }^{27}$

Esta explanação antropológica sobre as ideias transumanistas permite compreender que, na verdade, existem no seio do movimento antropologias que flutuam entre o humanismo iluminista e o pós-humanismo, sem descartar elementos transcendentes na percepção de transumanistas cristãos.

\section{Questões éticas emergentes}

As questões éticas que se seguem abandonam o campo das utopias, concentrando-se em duas problemáticas que tocam o núcleo prático do transumanismo: o melhoramento (enhancement) e uma noção de perfeição humana que conduziria à eugenia. O âmbito de análise são os problemas ligados à biotecnologia, ou mais precisamente, à construção dos corpos.

\subsection{Distinção entre terapia e melhoramento (enhancement)}

Existe uma discussão complexa no que se refere à distinção entre o uso terapêutico de uma pesquisa científica e o melhoramento. A terapia

26 Sobretudo a partir do Vaticano II, um diálogo fértil com a modernidade, também não pode ignorar o diálogo com a sua transformação atual, a que frequentemente se dá o nome de pós-modernidade. O presente volume pretende ser uma proposta de aproximação ao ambiente cultural contemporâneo. Começando por debater o próprio conceito de pós-modernidade e nele situar a questão do regresso do religioso, avança algumas propostas que podem redimensionar a teologia num contexto cultural já não tipicamente moderno. Salientam-se uma interpretação teológica de Nietzsche, uma avaliação crítica da teologia narrativa e uma crítica teológica da cibercultura. O que é a pós-modernidade? Que tem a teologia a ver com esse novo ambiente cultural? Trata-se de pura fragmentação relativista, que apenas deve ser condenada? Ou trata-se de um fenômeno bem mais complexo, lançando desafios importantes à fé cristã? O autor parte da segunda hipótese e oferece algumas propostas de interpretação que permitirão repensar o exercício da teologia num ambiente cultural em que já não são aceitos certos dogmas modernos. O novo lugar do religioso e da narrativa, o confronto criativo com Nietzsche, uma leitura da cibercultura... Esses e outros temas são avaliados teologicamente, como contributo para um diálogo cultural em curso. (DUQUE, João Manuel. Para o Diálogo com a Pós-Modernidade. [S. I.]: Paulus, 2016. p. 209, 212. [Coleção Teologia em Saída]). Ver também MARTINS, Hermínio. Experimentum Humanum Civilização Tecnológica e Condição Humana. Belo Horizonte: Fino Traço, 2012.

27 LACROIX, Xavier. O corpo reencontrado. Perspectiva Teológica, Belo Horizonte, v. 46, n. 129,2014 , p. $4-5$. 
consiste em ajudar o paciente a recuperar seu estado normal de saúde e natureza e, nesse sentido, a intervenção é moralmente aceitável. Diferentemente é o caso do melhoramento que consiste não em recuperar a saúde para o retorno a um estado normal, mas na intervenção do estado normal em vista de evolução dos atributos naturais do humano, o que pode levantar dúvidas no campo moral. ${ }^{28}$

Assim sendo, lança-se uma reflexão acerca do propósito da medicina no que se refere à tarefa terapêutica. Léo Pessini acredita que para além da terapia, as demais intervenções podem ser consideradas 'práticas extracurriculares'.$^{29}$ Entretanto, fato é que a questão não é tão simples e tampouco fácil de estabelecer essa completa divisão entre as situações terapêuticas e de melhoramento. Terapia e melhoramento interagem na atualidade. Basta mencionar o uso das vacinas que visam melhorar no organismo a capacidade de imunidade frente às doenças.

Embora esta distinção seja interessante [...], ela é inadequada para uma análise moral, diz o Repor da Comissão de Bioética dos EUA, que, embora utilizando a expressão, a categoriza como 'altamente problemática, abstrata e imprecisa'. Terapia e melhoramento são categorias que se entrecruzam: todas as terapias que foram bem-sucedidas são também terapias de aperfeiçoamento. Além disso, estes conceitos estão ligados à ideia de saúde e à sempre controversa ideia de normalidade. As diferenças entre saudável e doente nem sempre são tão evidentes. Seria terapia dar o hormônio de crescimento para um anão genético, mas não para uma pessoa anã que se sente infeliz justamente porque tem baixa estatura? Uma vez que sempre mais os cientistas acreditam que todos os traços da personalidade possuem uma base biológica, como distinguiremos 'defeito' biológico que permite a 'doença' da condição biológica que permite a timidez, melancolia ou irascibilidade? $?^{30}$

Assim, não é possível, de modo generalizado, emitir um julgamento moral sobre uso terapêutico das biotecnologias ou melhoramento, pois isso resultaria simplista e impreciso. Cada caso de ser analisado à parte, em sua especificidade e em seus méritos. Perigoso seria pensar em um uso simplesmente neutro das técnicas de melhoramento, como se esse uso não fosse bom nem mau, o que incorreria em ingenuidade. Toda a

28 Ver PESSINI, L., 2014, p.114-116.

"[...] a distinção parece ser útil, ao distinguir entre a obrigação central e mandatória da medicina (curar os doentes), e suas práticas extracurriculares, como por exemplo, as injeções de Botox e outros procedimentos cirúrgicos meramente cosméticos." (PESSINI L., 2014, p. 115). 
neutralidade no campo ético é relativa. ${ }^{31}$ Para cada caso, é importante perguntar: qual visão antropológica os sujeitos envolvidos adotam? Qual finalidade? Com quais recursos? Os direitos humanos estão assegurados em sua integralidade? As novas técnicas de melhoramento simplesmente estão aí como fatos inexoráveis, mas devem ser usadas com prudência.

\subsection{Transumanismo e eugenia}

A eugenia, conforme a tradução das raízes gregas da palavra: bem nascido, sugere a busca por uma seleção de seres humanos com características genéticas e hereditárias melhores para garantir um melhoramento nas novas gerações. ${ }^{32}$ Esse ideal coincide com a metodologia transumanista de melhoramento. Ambos, eugenia e transumanismo desejam um melhoramento do ser humano, mas a eugenia o faz mediante a seleção artificial da hereditariedade de seres com características mais desejadas (eugenia positiva) ou impedindo que haja a reprodução daqueles cujas características não são desejadas ou selecionadas (eugenia negativa). O melhoramento do transumanismo corre o risco de realizar uma eugenia indireta, uma vez que a probabilidade do acesso ao melhoramento indica não ser igualitário sendo reservado apenas para parte dos

31 "A aparência do discurso transumano traz a sensação de empoderamento (aperfeiçoamento pessoal, maximização da felicidade, erradicação de sofrimentos, etc.), que pode obscurecer a conscientização frente ao impacto das tecnologias emergentes. Posto isso, deve-se, sobretudo, pensar em como nossos valores serão alterados pela influência de novas tecnologias. Neste êxtase das promessas de emancipação e liberdade, convém recordar que ciência e tecnologia não são neutras ou objetivas, e, muito pelo contrário, mostram valores e interesses comerciais, assim como toda uma lógica de poder, própria de nosso contexto social e temporal. Criaremos um mundo voltado à função social da tecnologia, onde todos terão oportunidades e consciência das próprias capacidades de escolha? Difícil acreditar. Não nos deixemos levar pela fantasia. Deixemos essa para os livros." (FIORO, Germano Rigotti. Bem-vindos à nova eugenia: o transhumanismo. Empório do Direito: 2019. Disponível em: https:// emporiododireito.com.br/leitura/bem-vindos-a-nova-eugenia-o-transhumanismo).

32 "Com o propósito de aplicar os pressupostos da teoria da seleção natural ao ser humano, Francis Galton (1822-1911), primo de Darwin, em 1883, reunindo duas expressões gregas, cunhou o termo 'eugenia' ou 'bem nascido' [BLACK, 2003, p. 56]. A partir desse momento, eugenia passou a indicar as pretensões galtonianas de desenvolver uma ciência genuína sobre a hereditariedade humana que pudesse, através de instrumentação matemática e biológica, identificar os melhores membros - como se fazia com cavalos, porcos, cães ou qualquer animal -, portadores das melhores características, e estimular a sua reprodução, bem como encontrar os que representavam características degenerativas e, da mesma forma, evitar que se reproduzissem [cf. STEPAN, 1991, p. 1]." (DEL CONT, Valdeir. Francis Galton: Eugenia e hereditariedade. Scientiae Studia. São Paulo, 2008, v. 6, n. 2, abr./jun. Disponível em: https://www.scielo.br/scielo.php?pid=S1678-31662008000200004\&script=sci_arttext. Acesso em: 7 jul. 2020). 
seres humanos. ${ }^{33}$ É verdade que não é desejo dos transumanistas realizar uma espécie de seleção, mas sim que, livremente e respeitando a liberdade individual, os humanos evoluam gradativamente para um estágio pós-humano. Contudo, como abordou-se anteriormente, é questionável a possibilidade de total acesso ao melhoramento por parte de todos.

Jürgen Habermas (1929 - ) faz críticas às manipulações genéticas bem como a forma como o discurso sobre o melhoramento é apresentado. Apesar de conduzir a uma aceitação de parte da sociedade, na verdade não possui "a pretendida neutralidade científica e desvela seu caráter ideológico". ${ }^{34}$

Habermas denuncia que as conquistas da ciência afetam a auto-compreensão das pessoas como seres responsáveis. O grande problema é que as novas tecnologias e pesquisas cientificas obrigam a sociedade a aceitar um discurso público como correto para determinada cultura. Essa crítica pode ser aplicada aos avanços da biotecnologia na intervenção do genoma humano. Sobre isso Habermas cita o caráter de heterodeterminação, além da alteração do poder de ser-si-mesmo, sendo que tal intervenção é irreversivel. ${ }^{35}$

Habermas critica de modo muito pertinente o método de intervenção no genoma e aperfeiçoamento genético, a partir do elemento da liberdade tolhida do sujeito alterado geneticamente. Seu melhoramento seria feito sem o seu consentimento. A partir dessa abordagem, se poderia elencar problematizações éticas diante da noção de igualdade garantida pelo Estado, sob um ponto de vista sociopolítico bem como problemas no campo ético antropológico: na medida em que se manipula o corpo humano, não estaríamos tornando-o um objeto ${ }^{36}$

33 "O aprimoramento científico traz consigo um dilema moral: devemos ou não o levar adiante? Nas vias de um governo democrático, é de imaginar que, em tese, o Estado exerça seu papel como agente regulador na inserção das tecnologias emergentes no meio social, prezando pela segurança, precaução e extensão dos benefícios obtidos a todos os indivíduos - evitando, assim, a armadilha de uma eugenia liberal destinada à minoria." (FIORO, 2019, Disponível em: https://emporiododireito.com.br/leitura/ bem-vindos-a-nova-eugenia-o-transhumanismo).

34 SALVETTI, Ésio Francisco. Em busca de normatizações políticas e jurídicas que limitem a eugenia liberal: um estudo a partir do pensamento habermasiano. Filofazer Revista do Instituto Superior de Filosofia Berthier, Passo Fundo, n. 33, 2008, p. 80. SALVETTI É. F., 2008, p. 82-83.

"Com a decisão irreversível que uma pessoa toma em relação a constituição 'natural' de outra, surge uma relação interpessoal desconhecida até o presente momento. Esse novo tipo de relação fere nossa sensibilidade moral, pois forma um corpo estranho nas relações de reconhecimento legalmente institucionalizadas nas sociedades modernas. $\mathrm{Na}$ medida em que um indivíduo toma, no lugar de outro uma decisão irreversível, 
$\mathrm{Na}$ base da eugenia está o ideal de perfeição buscado a qualquer custo. O século XX, no decorrer de sua história, nos apresenta fatos que não podem ser desconsiderados na reflexão sobre a irrupção de um futuro pós-humano. Sabemos que a II Guerra Mundial, que produziu entre 50 a 70 milhões de mortes, esteve fundamentada sobre os princípios de eugenia como a raça pura ariana e a necessidade da extinção daqueles que eram considerados como inferiores. Uma espécie de seleção em vista do melhoramento. As noções de perfeição e de normalidade poderiam ser questionadas enquanto são definidas a partir de pressupostos não necessariamente estáveis. Assim, do ponto de vista ético, como pode-se dizer qual situação de vida consiste em maior ou menor perfeição? Por que determinada característica ou mesmo uma vida seria mais digna de ser mantida ou melhorada? "[...] Que critérios são utilizados para definir qual é a vida digna de ser vivida?" 37 .

A eugenia já se mostrou extremamente frágil em sua promessa de futuro aperfeiçoado. A eugenia nazista manifestou ao mundo a doença arrogante do perfeccionismo. Incoerência em nome da eugenia.

\section{Proposta cristã de sentido}

A antropologia hebraico-cristã está fundamentada no homem criado à "imagem de Deus" (Gn 1,26; 5,1.3; 9,6). Nessa expressão bíblica, entrevê-se no ser humano traços do mistério divino que garantem a ele uma identidade e uma missão únicas frente à criação. O personalismo cristão que daí surgiu, é um humanismo integral e solidário que ilumina as questões controversas postas pela revolução biotecnológica.

Nesta seção, analisam-se alguns elementos antropológicos presentes nos três primeiros capítulos do Gênesis, referentes aos relatos do primeiro casal de humanos, e que explicitam o sentido bíblico de imago Dei. Para isso, apresenta-se duas polaridades e um drama antropológi$\cos .^{38} \mathrm{~A}$ primeira polaridade dá-se entre a criaturalidade humana e a sua

interferindo na constituição orgânica do segundo, a simetria da responsabilidade, em princípio existente entre pessoas livres e iguais, torna-se limitada." (HABERMAS, Jürgen. O futuro da natureza humana: a caminho de uma eugenia liberal? São Paulo: Martins Fontes, 2010. p. 20).

37 SALVETTI É. F., 2008, p. 85.

38 A teodramática de Hans Urs von Balthasar serve de fundamentação para o diálogo com o transumanismo. Sua antropologia teológica está fundamentada no drama entre a liberdade finita e infinita, bem como em uma tríplice polaridade que Cristo iluminará: $1^{\mathrm{a}}$ tensão espírito e corpo; $2^{\mathrm{a}}$ homem e mulher; $3^{\circ}$ indivíduo e comunidade; ver BALTHASAR, H. U. von. Teodramática: Las personas del drama: El hombre en Dios. Vol. II. Trad.: Eloy Bueno de La Fuente e Jesús Camarero. Madrid: Encuentro, 2006. p. 333-361; 384-388. 
vocação à transcendência. Chama a atenção, nos dois relatos da criação, que o primeiro ressalte a ideia de o ser humano ser criado "à imagem e semelhança de Deus" $(\mathrm{Gn} 1,26)$ e o segundo afirme que ele foi feito do pó da terra $(\mathrm{Gn} 2,7)$. Esse contraste de ideias pode gerar um entendimento de que as narrações tratem da criação de dois seres diferentes, isto é, um espiritual e outro terreno. Mas essa aparente contradição, na verdade, expressa a consciência hebraica aberta a acolher o conjunto de relações e de particularidades que formam o humano. Ele é criatura e, ao mesmo tempo, é mais que criatura, chamado à transcendência ${ }^{39}$.

Para judeus e cristãos, essa polaridade sob hipótese alguma pode ser esquecida ou anulada, sob o risco de o homem iludir-se e perder-se a si mesmo. Como afirmado, o neognosticismo tecnológico deprecia o valor e a dignidade do corpo, relativizando a compreensão integral do humano contida em tal polaridade. Seguindo o pensamento bíblico, a pessoa não "tem" um corpo, ela "é" corporalidade. Não dispõe de seu corpo como se fosse um objeto, mas simplesmente o é, manifestando seu ser corporal como dom..$^{40} \mathrm{~A}$ afirmação da importância do corpo na tradição bíblica, longe de diminuir a dignidade do homem, desvela ao mesmo a verdade sobre si mesmo sem a qual ele não pode progredir autenticamente no caminho da transcendência. Não foi à toa que o cristianismo primitivo combateu severamente o gnosticismo devido ao seu menosprezo pela vulnerabilidade da carne. A consciência da sacralidade do corpo - como imago Dei - é uma pedra de toque para os cristãos no diálogo com o movimento transumanista, necessária para que se evitem barganhas em prol da obtenção de supostos avanços terapêuticos sem ética.

A segunda polaridade diz respeito à complementariedade do homem e da mulher. Em Gn 2,4b-25, afirma-se que Eva foi formada da costela de Adão para ser sua colaboradora, em relação de igualdade. Adão exclama ao vê-la: "esta, sim, é osso de meus ossos e carne de minha carne!" (Gn 2,23). Tal relato, incontido de alegria, nos remete à identidade relacional do ser humano: ele não é um ser andrógeno que se baste sozinho, nem alcança a felicidade sem compartilhar a sua vida e missão com os outros. Seguindo Karl Barth, a compreensão do Deus cristão como Trindade enriquece o entendimento sobre a pessoa humana como ser de relação, que se realiza na medida em que vive a dinâmica do

39 Luís Ladaria apresenta um breve histórico dessa tensão antropológica a partir da leitura bíblica de imago Dei; LADARIA, L. F. Antropologia teologica. 2. ed. Roma: Gregorian \& Biblical Press, 2012. p. 151-158. Para Balthasar, o homem, pelo seu espírito, encontra-se como o mediador entre a natureza e o divino; BALTHASAR, $\mathrm{H}$. U. von, 2006, p. 333-339.

40 Em Gn 2,7 o Criador sopra seu hálito (nefesh) sobre o homem modelado do barro, concedendo-lhe vida. Esse gesto divino remete a compreensão da vida como dom, e não como posse. 
amor. ${ }^{41}$ Quando se propõe uma compreensão mecanicista ou biologicista do homem, esse tende a reduzir-se à imagem da máquina ${ }^{42}$. Nesse caso, a complementariedade e as diferenças humanas desaparecem em nome de uma pretensa igualdade obtida por cálculos humanos.

O terceiro aspecto dá-se no drama entre as liberdades humana e divina, manifestada no relato dos primeiros passos de Adão e Eva no Jardim do Éden (Gn 3). Quando a serpente apareceu como uma intrusa no Jardim, propondo ao primeiro casal comer o fruto da árvore da ciência - que os levaria a serem como deuses -, proibido pelo Criador, desvelou-se a condição de liberdade humana com todas as suas consequências. Aqui, o drama não apresentará uma boa solução para o casal, visto que eles preferiram construir sua identidade e projetos, de pretensões divinas, em um âmbito que estivesse fora da comunhão com o Criador. Então, a imagem de Deus impressa no ser humano desfigurou-se pelo desejo de auto-salvação e de negação de sua criaturalidade. A expulsão do jardim marca o início de um longo e árduo caminho de tensões entre as liberdades finita e infinita. $\mathrm{O}$ transumanismo revela-se como mais um capítulo desse drama na medida em que manifesta a pretensão dos homens de "serem como deuses", utilizando o caminho do poder e da autossuficiência.

A proposta cristã imago Dei não anula ou ignora essas polaridades e drama. Acolhe-as como realidade humana inexorável, ao mesmo tempo em que apresenta a Jesus Cristo como o verdadeiro caminho de solução para essas. Ele é a verdadeira imagem do Pai, mostrando aos seres humanos que o caminho da transcendência não passa pelo poder e egoísmo, mas pelo amor. Nos mistérios de sua encarnação e de sua Páscoa, Jesus abre aos serres humanos o caminho para a realização de uma existência autenticamente livre e plena de sentido. Mostra pela obediência da cruz, que a liberdade divina não tolhe as possibilidades humanas, mas abre espaços ilimitados para que cada pessoa possa construir responsavelmente a si mesmo, pela doação de sua vida no amor, alcançando assim a plenitude, dom de perfeita comunhão com Deus e com as pessoas. ${ }^{43} \mathrm{~A}$ tecnologia, enquanto obra humana, pode contribuir para que o humano alcance essa plenitude, desde que haja a consciência de que ela é apenas

41 Foi K. Barth quem desenvolveu a teoria que vê a imagem de Deus na relação entre os homens: de alguma maneira, a comunhão vivida pelos seres humanos repete a relação existente entre as pessoas divinas; cf. BARTH, K. Kirchliche Dogmatik, v. III/1, Zürich, 1947, p. 204-206, apud LADARIA, L. F., 2012, p. 148.

42 Como constatou Jean Pierre Dupuy, nas pesquisas que desenvolvem a inteligência artificial e que diminuem as fronteiras entre máquina e cérebro: "A cibernética não é a antropomorfização da máquina, é, antes de tudo, a mecanização do humano" (DUPUY, J.P. L'esprit mécanise par lui-même. Le Débat, Paris, n. 109, p. 163, mar./ avr. 2000).

43 Cf. BALTHASAR, H. U. von, 2006, p. 175-309. 
um instrumento a serviço da comunhão e do desenvolvimento de todos os seres humanos.

Para o cristianismo existe uma meta muito clara a ser seguida, a saber, tornar-se parecido com Jesus Cristo. Assumir de maneira configurada o projeto de vida com seus sentimentos, pensamentos, atitudes e opções de Jesus Cristo. O humano perfeito para o cristianismo é aquele que realiza em sua vida a imagem de Cristo, enquanto um 'ser-para' (os outros). Ele quem revela ao ser humano qual o verdadeiro significado de sua natureza e dignidade. Em suma, a perfeição humana, para a teologia cristã, é tornar-se plenamente humano em Jesus Cristo.

Sendo assim, Cristo, o homem futuro, não é o homem para si e, sim, essencialmente, o homem aberto para os outros; ele é o homem futuro porque éo homem totalmente aberto. O ser humano que quer ficar apenas dentro de si mesmo é, portanto, o homem do passado que é preciso deixar para trás para podermos avançar. Isso significa, em outras palavras, que o futuro do ser humano está no 'ser para'. ${ }^{44}$

\section{Considerações finais}

Conforme as palavras da Declaração Transumanista que afirma "todo progresso seja mudança, mas nem toda mudança seja progresso", ${ }^{45}$ constatou-se que o futuro da humanidade está inexoravelmente marcado pelas mudanças das NBIC e que o sucesso delas, em um sentido integral, dependerá de uma profunda prudência, cautela e administração responsável, virtudes essas visibilizadas em políticas sociais de segurança. Será também necessário que as mudanças aconteçam em um plano econômico e social, com respeito à natureza e sentido de inclusão tecnológica das populações desprovidas de condições econômicas.

Quanto aos aspectos antropológicos que permeiam o transumanismo, constatou-se que a diversidade de concepções sobre o ser humano existentes ao interno desse movimento, não permite fazer uma avaliação moral uniforme, boa ou má sobre suas ideias. Contudo, a tendência comum, entre os seus ideólogos, na direção de uma radicalização do pensamento iluminista - e até o rompimento com esse - faz-nos realizar um diagnóstico de crise do humano ao interno do movimento. Não é à toa que discursos entusiasmados sobre as novas possibilidades do NBIC

44 RATZINGER, Joseph. Introdução ao Cristianismo: preleções sobre o Símbolo Apostólico com um novo ensaio introdutório. São Paulo: Loyola, 2004. p. 180

45 BAILY et al., 1998, Disponível em: https://humanityplus.org/philosophy/transhumanist-declaration/. 
para o indivíduo, geralmente escondem uma antropologia pessimista, resistente em aceitar a finitude, o sofrimento e a vulnerabilidade da carne. O neognosticismo tecnológico que daí nasce, de características imanentes, torna-se um espaço ideológico atrativo para pesquisas pouco éticas e desrespeitosas para com a dignidade humana.

Como possibilidade de diálogo, apontamos a antropologia cristã com sua concepção integral e solidária de ser humano, embasada na concepção bíblica de imago Dei. Nessa antropologia, as novas técnicas não são condenadas enquanto tais, mas são avaliadas em seu caráter verdadeiramente humano. Então, o melhoramento (enhancement) não levará em conta somente o aspecto biológico - como o aumento da resistência às doenças. Contará também com o aprendizado da resiliência perante os momentos inevitáveis de dor e de abandono, bem como a aquisição da empatia e da abnegação pessoal a fim de se solidarizar com os sofrimentos e a morte do outro. Em suma, os homens do passado, do presente e do futuro permanecem carentes da busca de um aperfeiçoamento que não depende da técnica nem da genética, mas sim de sua configuração com a atitude fundamental de vida daquele que conheceu a morte e a venceu, Jesus de Nazaré.

\section{Referências}

ANTONIO, K. F. Transhumanismo e suas oscilações prometeico-faústicas: tecnoapoteose na era da tecnociência demiúrgica. Natal: PPGFIL, 2018. p. 139-283. Disponível em: https://issuu.com/j00kun/ docs/keoma_ferreira_antonio_-_transhumanismo_e_suas_osc. Acesso em: 5 jul. 2020.

BAILY, Doug. Transhumanist Declaration, 1998. Disponível em: https:// humanityplus.org/philosophy/transhumanist-declaration/.

BALTHASAR, H. U. von. Teodramática: Las personas del drama: El hombre en Dios. Vol. II. Trad.: Eloy Bueno de La Fuente e Jesús Camarero. Madrid: Encuentro, 2006.

BOSTROM, Nick. Valores Transhumanistas. Instituto Ética, Racionalidade e Futuro da Humanidade: 2005, p. 8-9. Disponível em: http://www. ierfh.org/br.txt/ValoresTranshumanistas2005.pdf.

BOSTRON, N. A History of Transhumanity Thought. 2011, p. 30. Disponível em: https://www.nickbostrom.com/papers/history.pdf. Acesso em: 5 jul. 2020.

CAMURÇA, Marcelo. 'Religiosidades científicas' hoje: entre o secular e o religioso. In: CRUZ, Eduardo R. da. Teologia e Ciências Naturais: 
Teologia da Criação, Ciências e Tecnologia em diálogo. São Paulo: Paulinas, 2011.

COMISSÃO TEOLÓGICA INTERNACIONAL. Em busca de uma ética universal: novo olhar sobre a lei natural. Disponível em: http://www.vatican.va/roman_curia/congregations/cfaith/cti_documents/rc_con_cfaith_doc_20090520_legge-naturale_po.html. Acesso em: 12 jul. $20 \overline{2} 0$.

CORREA, Rafael Murilo. Entenda o que é a quarta revolução industrial e quais seus impactos sociais. 2018. Disponível em: https://euax. com.br/2018/06/quarta-revolucao-industrial-impactos/. Acesso em: 5 jul. 2020.

DEL CONT, Valdeir. Francis Galton: Eugenia e hereditariedade. Scientiae Studia. São Paulo, 2008, v. 6, n. 2, abr.-jun. Disponível em: https://www. scielo.br/scielo.php?pid=S1678-31662008000200004\&script=sci_arttext.

DUQUE, João Manuel. Para o Diálogo com a Pós-Modernidade. [S. l.]: Paulus, 2016. (Coleção Teologia em Saída).

DUPUY, J. P. L'esprit mécanise par lui-même. Le Dêbat. Paris, n. 109, p. 163 , mar.-avr. 2000

FERRY, Luc. A Revolução transumanista: entrevista concedida a Jorge Forbes para o prefácio da edição brasileira do livro A Revolução transumanista. In: Instituto da Psicanálise Lacaniana, 2018. Disponível em: http://www.ipla.com.br/conteudos/artigos/a-revolucao-transumanista/.

FIORO, Germano Rigotti. Bem-vindos à nova eugenia: o transhumanismo. Empório do Direito: 2019. Disponível em: https://emporiododireito. com.br/leitura/bem-vindos-a-nova-eugenia-o-transhumanismo.

HABERMAS, Jürgen. O futuro da natureza humana: a caminho de uma eugenia liberal? São Paulo: Martins Fontes, 2004.

HAMMES, Érico. Transumanismo e Pós-humanismo: uma aproximação ético-teológica. Perspectiva Teológica, Belo Horizonte, v. 50, n. 3, p. 431-452, 2018.

HARARI, Yuval N. Sapiens: uma breve história da humanidade, 38. ed. Porto Alegre: L\&PM, 2018. p. 236-245; 315-385.

HARARI, Yuval N. Homo Deus: uma breve história do amanhã, São Paulo: Companhia das Letras, 2016.

HUXLEY, J. New Bottles for New Wine. London: Chatto and Windus, 1957.

LACROIX, Xavier. O corpo reencontrado. Perspectiva Teológica, Belo Horizonte, v. 46, n. 129, p. 4-5, 2014. 
LADARIA, L. F. Antropologia teologica. 2. ed. Roma: Gregorian \& Biblical Press, 2012.

LIGHTHALL, W. D. The Law of Cosmic Evolutionary Adaptation: An Interpretation of Recent Thought. Ottawa: Royal Society of Canada, 1940.

MARTINS, Hermínio. Experimentum Humanum Civilização Tecnológica e Condição Humana. Belo Horizonte: Fino Traço, 2012.

MORE, M. Principles of Extropy. 2003. Disponível em: https://web. archive.org/web/20131015142449/http://extropy.org/principles.htm. Acesso em: 5 jul. 2020.

PEARCE, David. As cinco razões pelas quais o transumanismo é capaz de eliminar o sofrimento, 2011. Disponível em: https://www.hedweb. com/transhumanism/cinco-razoes.html. Acesso em: 20 out. 2019.

PESSINI, Leo. Bioética e o futuro pós-humano: Ideologia ou utopia, ameaça ou esperança? Encontros Teológicos, Florianópolis, n. 67, p. 107-130, 2014.

PICO DELLA MIRANDOLA, G. Discurso sobre a dignidade do homem. Trad. de Maria de Lurdes Sirgado Ganho. Lisboa: Edições 70, 2001.

RANISCH, Robert; SORGNER, S. Lorenz (org.). Post - and Transhumanism: an introduction. [S. l.]: Peter Lang Edition, 2014.

RAHNER, K. Sämtliche Werke: Verantwortung der Theologie. Im Dialog mit Naturwissenschaften und Gesellschaftstheorie: BD 15. Freiburg: Verlag Herder, 2020. V. 15.

RATZINGER, Joseph. Introdução ao Cristianismo: preleções sobre o Símbolo Apostólico com um novo ensaio introdutório. São Paulo: Loyola, 2005.

RIVAS GARCÍA, Ricardo, La crisis del humanismo: una revisión y reconstrucción de los supuestos del humanismo cristiano, ante los desafíos del antihumanismo contemporáneo. Franciscanum, v. LXI, n. 172, 2019.

SALVETTI, Ésio Francisco. Em busca de normatizações políticas e jurídicas que limitem a eugenia liberal: um estudo a partir do pensamento habermasiano. Filosofazer Revista do Instituto Superior de Filosofia Berthier, Passo Fundo, n. 33, p. 79-89, 2008. 